PROBLEMS

OF EDUCATION

IN THE $21^{\text {st }}$ CENTURY

Vol. 79, No. 1, 2021

\section{WRITING A SCIENTIFIC ARTICLE: FOCUSED DISCUSSION AND RATIONAL CONCLUSIONS}

\author{
Vincentas Lamanauskas \\ Vilnius University Šiauliai Academy, Lithuania \\ E-mail: vincentas.lamanauskas@sa.vu.It
}

Writing a scientific article does not end with a description of the summarized results. Conclusions and implications remain a crucial part of the article. The previous papers portrayed the most important aspects of the title, summary (Lamanauskas, 2019a), accurate introduction (Lamanauskas, 2019b) and research methodology (Lamanauskas, 2020a) of the article and discussed the features of the presented results (Lamanauskas, 2020b). Discussion is also accepted as an equally important structural part of the scientific article (particularly in the case of describing an experimental / empirical study). Thus, this section summarizes the results of the conducted study. However, this piece of writing is not intended to provide all possible options for discussion and drawing conclusions due to the fact that the specificity of article preparation varies in each field of science. In addition, it depends on the requirements set by scientific / research journals (or other publications) and publishing policy. Therefore, this editorial more concentrates on the general aspects of preparing the above mentioned parts of the article.

\title{
Discussion
}

Writing discussion is definitely one of the most difficult tasks. Researchers note that discussion is very important to readers, however, it is extremely challenging for authors (Drotar, 2009). Some authors argue this is the trickiest part of the scientific article (Vieira et al. 2019), defining the content of which is more difficult than describing the content of other sections (Day $\&$ Gastel, 2006). Several researchers (Derntl, 2014) state that the purpose of the discussion of the article is to draw general conclusions and present implications arising from the results obtained, but conversely such a position is not correct. Thus, scientific articles frequently contain extremely superficial, incomplete discussions that often have no added value, or the latter is extremely scarce. Discussion primarily focuses on interpreting the results obtained in a particular study considering and evaluating other already published results. At the same time, recent information from scientific data sources provided in the introductory part is added thus including new sources. A part of researchers consider discussion to be the last chance to 'sell' the written article (Bavdekar, 2015), i.e. the marketing function of the scientific article is emphasized. In other words, the purpose of discussion is to expand knowledge in the field of study incorporating the obtained results into the context of the previous research studies (Shah, 2016). An important point is that discussion is dedicated to the reader, and therefore must help understand the study (Hess, 2004), which is to be accepted as an essential focus on discussion. Nevertheless, no detailed and unified scheme for how discussion should be written is available. For instance, APA 7th ed provides that the article 'can be organized in many ways, and organization generally depends on the paper type' (Publication Manual..., 2020, p. 39). Despite the fact that the preparation of discussion is hardly regulated in any way, still, certain methodological requirements and good practice in academic writing exist. The primary purpose of discussion is to explain the results obtained in one way or another to substantiate 
the formulated conclusions. Therefore, individually gathered evidence/results and information collected by other researchers are used. Disclosing the methods and level the results obtained confirm/refute the findings of the previous research is of utmost importance. Yet, this does not mean discussion covers the complete results of the carried out research. Bem (2004) suggests it is wrong when the author(s) put a lot of effort to discuss each and every result/finding.

Frequently, read and/or reviewed scientific articles have no clear distinction between research results and discussion. However, some cases are justified, particularly those of nonempirical studies. The situation when the results of the carried out research are confused with the papers of other researchers plays a very negative role. This way, the contribution of a particular study remains unclear. Thus, a view that the results and discussion of research should be written as the separate sections of the scientific article is accepted. Such a distinction allows the reader to clearly identify what has been found in relation to the current situation in a particular field of science and with respect to the contribution of the author(s). Therefore, the sections such as 'Discussion and Conclusions', 'Discussion with Conclusion', 'Results and Discussion', 'Summary and Discussion', 'Conclusions and Discussion', etc. should be avoided in order not to create a 'blend' containing 'all in one'. Clear distinction should be maintained between research results, discussion and research conclusions and implications.

Another fairly common practice demonstrates discussion on research results to be limited to local scientific sources, especially if a local, narrow-ranging study has been done. In such cases, it should still be appropriate for researchers to 'enrich' discussion referring to the latest international scientific sources. Equally possible is the opposite situation when a comprehensive international study has been made, but the discussion of the provided results is based on several research sources at the local level.

For writing the discussion section, the following points are usually distinguished: first, the main purpose of research is recalled; second, the most important research results are refined; third, the similarities and differences of the obtained results in the context of the previous research are disclosed. Hence, the reader has the opportunity to compare research results, to evaluate research novelty and to assess the scientific contribution of the performed research. A critical position of the authors themselves on the conducted research is equally important trying to identify whether the expected results have been achieved. It is also relevant to highlight the uniqueness of the results and to develop discussion by keeping this position central. On the other hand, mentioning the shortcomings/weaknesses of the performed study by the author of the research him/herself rather than by a reviewer at a later stage is useful and characteristic of every research done. Table 1 provides a few examples of the appropriate/inappropriate elements of discussion.

\section{Table 1}

\section{Appropriate/Inappropriate Elements of Discussion}

\begin{tabular}{|c|c|}
\hline Inappropriate & Appropriate \\
\hline $\begin{array}{l}\text { Research results are repeated; } \\
\text { Conclusion-like statements are formulated; } \\
\text { previous research is extensively cited; } \\
\text { the results are presented as absolutely accurate, clear } \\
\text { and certain; } \\
\text { the unjustified criticism of the previous research; } \\
\text { doubtful, irrelevant statements and unsubstantiated } \\
\text { reasoning are included; } \\
\text { tables and/or figures are provided; } \\
\text { indirect issues and/or problems are discussed. }\end{array}$ & $\begin{array}{l}\text { Statements confirming/refuting the hypothesis (es); } \\
\text { interpretations of research results; } \\
\text { disclosure of the relevance of research results; } \\
\text { possible alternative interpretations of the results are } \\
\text { presented; } \\
\text { the relationship with the results of the previous } \\
\text { research is shown; } \\
\text { possible exceptions, similarities and differences are } \\
\text { indicated; } \\
\text { paradoxical, unexpected or unconvincing results are } \\
\text { explained. }\end{array}$ \\
\hline
\end{tabular}


PROBLEMS

OF EDUCATION

IN THE $21^{\text {st }}$ CENTURY

Vol. 79 , No. 1,202

6

There is no need to repeat the obtained results in the discussion section. Thus, it is advisable to focus on the (in the researcher opinion) most relevant results and discuss them in great detail. An emphasis should be placed on prioritizing the main arguments of possible reason(s) on the results obtained and then linking them with the current scientific literature. Discussion is frequently written as if it was an overview of the other (previous) studies rather than a strong discussion of research results with respect to work done by others, and such works predominate. A variety of articles mainly simulate discussion (Table 2).

\section{Table 2}

\section{The Examples of Inappropriate Discussion}

Example of discussion
Discussion
The methodological education of teachers is a long-term process in which,
through learning, practical work and research activities, knowledge is
completed and skills and abilities developed. The competencies of teachers
are undoubtedly developing more rapidly, and statistical information as a part
of professional competences becomes everyday life, which is a significant
improvement compared to some past times when teachers were only lecturers.
Based on theoretical considerations and research of attitudes of teachers-
reflexive practitioners, we tried to determine their attitudes regarding the
importance of methodological education for the improvement of educational
practice and personal improvement. The aim of this research was to find out
whether teachers, reflexive practitioners, conduct research in their educational
work, consider it an important segment of their work, whether they recognize
the importance of action research to improve and change their practice and
how much they are ready for in-service training.

\section{Discussion}

This research conceptualized and empirically proved that a distributed form of leadership is one of the crucial elements in the current democratic scenario of school management if the effectiveness of education is a desired goal. It has proved itself for improving students' learning outcome and the teachers' self-efficacy. Furthermore, it enhances the faculty morale and the level of job satisfaction. The quality of deliverance improved where the faculty and staff were engaged and involved in the decision making process. Effective interpersonal skills on the part of teachers were seen where they were trusted in power sharing and decision making. This situation helps improving capacity building and improvement in academia.

\section{Comment}

The provided example mainly contains no discussion - only the imitation of the latter. The essence and comparative analysis of the performed research are not provided, which impedes understanding the relevance of the results of the conducted research. Critical discussion on other studies provides an insight into the new obtained data and the contribution of each performed study to the investigated problem. The discussion provides unnecessary information.

The presented example encompasses the same shortcomings discussed above and is merely the imitation of discussion (written because it is necessary). The provided example failed to reveal the goals that had not been established and did not indicate space for further research.

Note: The language used in the examples given has not been corrected

To sum up, several features of discussion can be identified:

- In the case the section of research results focuses on the answer to the question What results have been obtained?, the discussion section concentrates on the answers to the questions What is the implication of the results obtained?, What is the importance of the results?, etc.

- The discussion section summarizes the main results and interprets the significance of findings.

- In contrast to the section of research results of the article, a focus is on clarifying rather than on repeating the obtained results. 
- No new results are presented, and no statements are made until the obtained results are substantiated.

- Only text is most frequently used avoiding the items such as Figures and/or Tables. If necessary, links to non-textual elements by providing references to the latter are created.

- The meaning of the obtained results and the connection of the results with the research problem are explained.

- The discussion section specifies the restrictions (limitations) of the study. A crucial point is that research results should not be unduly overestimated. Researchers note that the assessment of limitations is a practical way to correct human error thus enhancing science (Vuong, 2020). section.

- It is appropriate to briefly indicate the points that need special attention in the discussion

- Categorical statements are avoided.

- In a sense, discussion is a mirror image (refection) of the Introduction.

Certainly, one could mention a number of other equally significant points of writing discussion. Authors sometimes consider discussion as conclusions, and therefore do not present the Conclusions section separately, which is a wrong approach. Discussion and conclusions have different meanings and purposes. Therefore, there is no need to confuse and do a 'mix' of both. Similarly, academic writing practice points to the examples where the discussion section is not written, and instead, the conclusion section is provided thus drawing conclusions and discussing research results together with works done by other researchers. Such an approach is considered to be methodologically unfounded and makes complicated the clarity, understanding and consistency of the drawn research conclusions. It seems to be useful to recall that readers/ users often start reading the article from conclusions in order to faster learn the most important scientific issues. Thus, conclusions must be prepared with particular care. Another important aspect has to do with writing the article itself. In this case, the style of article writing appears as one of the most important prerequisites for a good paper. The scientific style of the research article must be the same. When an article is prepared by several researchers, the authors share responsibility for preparing the individual parts of the paper. Hence, there is a high probability that, for example, the discussion section will be prepared by one author and the other sections by other authors. Combining all sections of the article into a single whole becomes a significant challenge. The mission of the main author is usually to ensure that the entire article is written in the same style. The scope of discussion is also worth mentioning. Practical experience suggests that the discussion section of the paper should not go beyond the introduction to the article (generally, discussion should not exceed two A4 pages). According to other authors, discussion should consist of 6-7 paragraphs each of which should not exceed 200 words (Şanlı et al. 2013). Finally, with reference to the practice of scientific writing, discussion is the least readable part of the article, and therefore writing this section is highly responsible.

\section{Conclusions and Implications}

The Conclusions section of the scientific article is no less significant structural part. Actually, this is the most important section that should fully concentrate on the made research and the refined results. Moreover, conclusions must also cover new ideas and insights. Researchers validly note that conclusions are very difficult to write due to the fact that on the one hand, they must be extremely concise and concentrated, whereas on the other hand, they must be drawn in a sufficiently detailed way (Poviliūnas \& Ramanauskas, 2008). In addition, conclusions provide the core of the research done and other components such as recommendations, implications of the study, etc. (Zamani \& Ebadi, 2016). Conclusions are treated as the purification of the 
Vincentas LAMANAUSKAS. Writing a scientific article: Focused discussion and rational conclusions

PROBLEMS

OF EDUCATION

IN THE $21^{\text {st }}$ CENTURY

Vol. 79 , No. 1,202

gist of the carried out research, the actual generalization of thoughts and the revelation of the importance of ideas. Providing insights and implications creates the opportunity for the reader/ user to look at the investigated topic/problem in a new (different) way. Thus, summarizing the main conclusion of the study is crucial. At the same time, possible repetitions should be avoided properly selecting new phrases and wordings. Although this editorial is not aimed at going into more detail in linguistic peculiarities, however, the use of the language must be considered. For instance, to describe conclusions, the Russian language most frequently uses the term 'Zakljuchenie' (Rus. Заключение) rather than 'vyvody' (Rus. Выводы). The latter is closer to the English term 'Conclusions (Latin 'conclusio'). In the context of the Russian language, conclusions are accepted as a short, concise summary of the main results in the form of short sentences. It looks like a finished thought. 'Zakljuchenie' is perceived as the reflection of the content of the main article describing research results obtained during the conducted research (frequently written in the format of the numbered theses). It is like a short retelling or summary of the content of the main article. In this respect, the introduced concept is a bit closer to discussion, however, it is not real discussion in the context of a Western academic writing culture. This brief linguistic look is significant as it contributes to a better understanding of academic writing, i.e. an appropriate academic style is determined by traditions (Chugrov, 2015).

The Conclusions section usually consists of two basic parts. The first part clearly sets out the main conclusions and reveals the core and significance of the research. An important point is to reveal the methods and level used for solving the research problem and possible knowledge gaps in the researched area. Simultaneously, further directions for possible research are proposed. Conclusions may be formulated in various ways, for example, numbered or unnumbered. Nevertheless, a more appropriate format points to the conclusions presented in concise and coherent text lacking the format of theses. The formulation of conclusions focuses on seeking to answer the research questions raised. A possibly high correlation between the main purpose of the study, research questions and conclusions should be established. Finally, highlighting achievements in particular research using the below formulations is of crucial importance:

- It has been found that ...;

- It has been established that ...;

- It has been developed that ...;

- It has been confirmed that ...;

- It has been revealed

- It has been measured ... etc.

The formulation of conclusions should aim to reveal how the carried out research contributes to closing a research gap in a particular field of science and demonstrate the potential contribution of research to scientific treasure in general. Overall, conclusions must be drawn in an understandable and valid manner (Table 3). 
Table 3

Incorrect/Inappropriate Wording in the Conclusions Section

\begin{tabular}{|c|c|}
\hline Examples & Comment \\
\hline $\begin{array}{l}\text { Based on the results achieved in this study, it can be concluded as } \\
\text { follows ... } \\
\text { Based on the above conclusions, it is suggested that some things as } \\
\text { follows ... } \\
\text { From the results obtained, it can be concluded that ... } \\
\text { At the end, as expected, we can conclude that ... } \\
\text { Based on the analysis of the empirical material, conclusions have } \\
\text { been drawn that will be helpful ... } \\
\text { In conclusion, this study highlights that ... } \\
\text { In the opinion of the great thinkers above, it can be concluded that ... } \\
\text { The present study has drawn the following conclusions ... } \\
\text { On the whole, as a conclusion, working together seems to be highly } \\
\text { valued ... } \\
\text { The study and analysis of the literature on education allows us to } \\
\text { make the following conclusions ... } \\
\text { Based on the results of research and discussion elaborated in the first } \\
\text { chapter to the fourth chapter, we came to the following conclusions ... } \\
\text { As a conclusion, it can be added that ... } \\
\text { The results of literature studies and analysis show that it is still needs } \\
\text { a long time and spirit to keep fighting at a better level ... } \\
\text { In the opinion of the authors of this paper ... } \\
\text { More emphasis should be placed on ... } \\
\text { The conclusion of this research is ... } \\
\text { To the best of the authors' knowledge, this is the first research to ... } \\
\text { One conclusion that can be drawn is ... } \\
\text { Ultimately, this article's conclusions and implications are ... } \\
\text { The findings from the study suggest that ... }\end{array}$ & $\begin{array}{l}\text { The examples clearly show that } \\
\text { conclusions should not be started } \\
\text { using such sentences. First, repeating } \\
\text { 'conclusions' is inappropriate, because } \\
\text { it makes evident that a certain section } \\
\text { of the article focuses particularly on } \\
\text { conclusions. Second, vague, trivial, } \\
\text { repetitive sentences are used at the } \\
\text { beginning of the text. Some examples } \\
\text { demonstrate an attempt to describe } \\
\text { suggestions/recommendations } \\
\text { rather than specific, conceptualized } \\
\text { conclusions, i.e. show the significance } \\
\text { and essence of particular research. } \\
\text { Conclusions cannot be treated as } \\
\text { only a few generally accepted words } \\
\text { or sentences. On the contrary, } \\
\text { research results should be thoroughly } \\
\text { formulated and clearly and concisely } \\
\text { reflect the main theoretical and / or } \\
\text { empirical results of the study. Any } \\
\text { new arguments and / or conclusions } \\
\text { made by other researchers should } \\
\text { be avoided. The basic point is to } \\
\text { keep in mind that conclusions and } \\
\text { recommendations must be originally } \\
\text { arising from the results of a particular } \\
\text { study. }\end{array}$ \\
\hline
\end{tabular}

Note: The language used in the examples given has not been corrected

Conclusions cannot be reminiscent of discussion, which is an extremely negative point. Conditionally, one can accept such situation as the second discussion, which means that the author provides various quotations, references to the works of other researchers, etc. when formulating and presenting conclusions. It is considered conclusions should avoid references to other sources. All references are provided in the literature review, introduction to the article, description of the research methodology and/or discussion (discussion of research results). It is expected that conclusions will be exclusively original and based only on the specific study conducted. In addition, the so-called generalized conclusions of the article are not written keeping in mind the study done and research results reported.

Thus, for drawing conclusions,

- describing every detail is not intended;

- abstract is not repeated;

- no citations or other references are made;

- no discussion is generated;

- the language used is short and precise;

- conclusion statements must exclude any empirical values (expressions) of research results, citations, tables and/or figures are eliminated. 
PROBLEMS

OF EDUCATION

IN THE $21^{\text {st }}$ CENTURY

Vol. 79 , No. 1,2021

10

The Conclusions section is frequently written very superficially, vaguely and trivially. A few typical examples of drawing conclusions are given below in Table 4.

\section{Table 4}

The Examples Found in the Conclusions Section

\begin{tabular}{ll}
\hline \multicolumn{1}{c}{ Text used in the Conclusions section } & \multicolumn{1}{c}{ Comment } \\
\hline $\begin{array}{l}\text { Conclusions } \\
\text { Based on the results and discussion shows that the indicators of } \\
\text { adoption of scientific attitude are quite good, the pleasure in learning } \\
\begin{array}{l}\text { science is good, and interest to spare time is also quite good. The } \\
\text { overall attitude of students to science subjects is quite well. }\end{array}\end{array}$ & $\begin{array}{l}\text { The example provides absolutely trivial } \\
\text { conclusions. The author agrees that } \\
\text { results are apparently hasty alleged and are } \\
\text { not based on any results. }\end{array}$
\end{tabular}

\section{Conclusions}

Current research proposes that further research can be done in investigating the vocabulary learning strategies used among engineering students with different fields of study such as marine engineering, biomedical engineering and aerospace engineering. It would be interesting to find out if there are significant differences in using vocabulary learning strategies among other engineering fields. Current research also suggests further research to be conducted in other universities that offers more technical courses other than engineering and science. It would be beneficial if further research can reveal the vocabulary learning strategies employed by students majoring in other technical courses such as medical, law and accounting. Furthermore, further research can select a specific strategy from the taxonomy and investigate on the effect of the The example does not provide any conclusions, although in line to the scope of the text, these could be the conceptualized results of the study. However, the very first and subsequent sentences make suggestions such as 'research proposes' and 'research suggests'. Other sentences include structures like 'would be interesting', 'would be beneficial', etc., which is basically intentions. After reading the text, no conclusions are found, i.e. no information on the research made, the results obtained, determined, etc. is provided strategy on students' vocabulary acquisition.

Note: The language used in the examples given has not been corrected

The second part of this section usually focuses on implications and possible practical recommendations. In the cases of discussing scientific articles in the field of social sciences, the latter usually describe applied empirical research. Therefore, recommendations and suggestions for the field of science etc. are desirable. Recommendations must be targeted, i.e. indicate the audience they are addressed, concise and clear. However, this is not supposed to be an obligatory attribute of the article. There are cases where making recommendations is hardly appropriate. Dull and trivial recommendations should be evaded. On the contrary, if possible, providing specific solutions to the research problem seems to be appropriate. For making recommendations, the interpretations of a general character, for instance

- to improve,

- to advance,

- to seek,

- to expect,

- $\quad$ to activate, etc. should be omitted.

A position on conclusions as a whole primarily aims to answer the question what methods and means have been used for achieving the aim of the research conducted. The final formulation of conclusions shows the achieved degree of the effectiveness of the study performed. From a structural point of view, it makes sense to write the Conclusions section consisting of two or three paragraphs (introductory part, implications and insights, recommendations and suggestions). An important point is the indication of what is the added value of the current research to the previous reports. It is obligatory to ensure that the reported new scientific information is significant for readers/users (mainly at the international level). 
Note

Some examples have been taken from the manuscripts submitted for journals Journal of Baltic Science Education and Problems of Education in the 21 $1^{\text {st }}$ Century.

\section{References}

Bavdekar, S. B. (2015). Writing the discussion section: Describing the significance of the study findings. Journal of the Association of Physicians of India, 63, 40-42.

Bem, D. J. (2004). Writing the empirical journal article. In J. M. Darley, M. P. Zanna, \& H. L. Roediger III (Eds.), The complete academic: A career guide (pp. 185-219). American Psychological Association.

Chugrov, S. V. (2015). Nauchnaja stat'ja: plod tvorchestva, remesla ili ozarenija? [Scientific article: A fruit of creative art, craft, or revelation?]. Polis. Political Studies, 3, 160-176. http://dx.doi.org/10.17976/jpps/2015.03.11

Day, R. A., \& Gastel, B. (2006). How to write and publish a scientific paper. Greenwood Press.

Derntl, M. (2014). Basics of research paper writing and publishing. International Journal of Technology Enhanced Learning, 6(2), 105-123. https://doi.org/10.1504/IJTEL.2014.066856

Drotar, D. (2009). Editorial: How to write an effective results and discussion for the Journal of Pediatric Psychology. Journal of Pediatric Psychology, 34(4), 339-343. https://doi.org/10.1093/jpepsy/jsp014

Hess, D. R. (2004). How to write an effective discussion. Respiratory Care, 49(10), 1238-1241. http://rc.rcjournal.com/content/49/10/1238

Lamanauskas, V. (2019a). Scientific article preparation: Title, abstract and keywords. Problems of Education in the 21st Century, 77(4), 456-462. https://doi.org/10.33225/pec/19.77.456

Lamanauskas, V. (2019b). Scientific article preparation: A comprehensive introduction. Problems of Education in the 21st Century, 77(6), 688-694. https://doi.org/10.33225/pec/19.77.688

Lamanauskas, V. (2020a). Scientfic article preparation: Methodology description. Problems of Education in the 21st Century, 78(2), 136-146. https://doi.org/10.33225/pec/20.78.136

Lamanauskas, V. (2020b). Writing a scientific article: Describing results. Problems of Education in the 21st Century, 78(4), 472-485. https://doi.org/10.33225/pec/20.78.472

Poviliūnas, A., \& Ramanauskas, J. (2008). Vadybos ir administravimo mokslinio straipsnio savitumai ir struktūra [Features and structure of scientific article in the management and administration sciences]. Vadybos mokslas ir studijos - kaimo verslu ir ju infrastruktūros plètrai = Management Theory and Studies for Rural Business and Infrastructure Development, 15(4), 6-13.

Publication Manual of the American Psychological Association, 7th ed. (2020). American Psychological Association.

Shah, J. (2016). How to write 'discussions, conclusions' in scientific journal article. Journal of Patan Academy of Health Sciences, 3(2), 1-2.

Şanlı, Ö., Erdem, S., \& Tefik, T. (2013). How to write a discussion section? Turkish Journal of Urology, 39(Suppl 1), 20-24. https://doi.org/10.5152/tud.2013.049

Vieira, R. F., Lima, R. C. D., \& Mizubuti, E. S. G. (2019). How to write the discussion section of a scientific article. Acta Scientiarum. Agronomy, 41, Article e42621. https://doi.org/10.4025/actasciagron.v41i1.42621

Vuong, Q. -H. (2020). Reform retractions to make them more transparent. Nature, 582, 149. https://doi.org/10.1038/d41586-020-01694-x

Zamani, G., \& Ebadi, S. (2016). Move analysis of the conclusion sections of research papers in Persian and English. Cypriot Journal of Educational Science, 11(1), 09-20. https://eric.ed.gov/?id=EJ1140659 
PROBLEMS

OF EDUCATION

IN THE $21^{\text {st }}$ CENTURY

Vol. 79 , No. 1,2021

Cite as: Lamanauskas, V. (2021). Writing a scientific article: Focused discussion and rational conclusions. Problems of Education in the $21^{\text {st }}$ Century, 79(1), 4-12. https://doi.org/10.33225/pec/21.79.04

Vincentas Lamanauskas

$\mathrm{PhD}$, Professor, Senior Researcher, Vilnius University Šiauliai Academy, Institute of Education, P. Visinskio Street 25-119, LT-76351 Siauliai, Lithuania.

E-mail: vincentas.lamanauskas@sa.vu.lt

Website: http://www.lamanauskas.puslapiai.ltt;

https://www.researchgate.net/profile/Vincentas_Lamanauskas

ORCID ID: http://orcid.org/0000-0002-4130-7899 